CELSI Discussion Paper No. 37

THE EFFECT OF

UNEMP LOYMENT BENEFI T

GENEROSI TY ON

UNEMPLOYMENT DURATI ON:

QUASI - EXPERI MENTAL

EVI DENCE FROM SLOVENIA

J anuary 2016

MATI J A VODOPI VEC

SUZANA LAPORSEK

PRI MOZ DOLENC

MI LAN VODOPI VEC

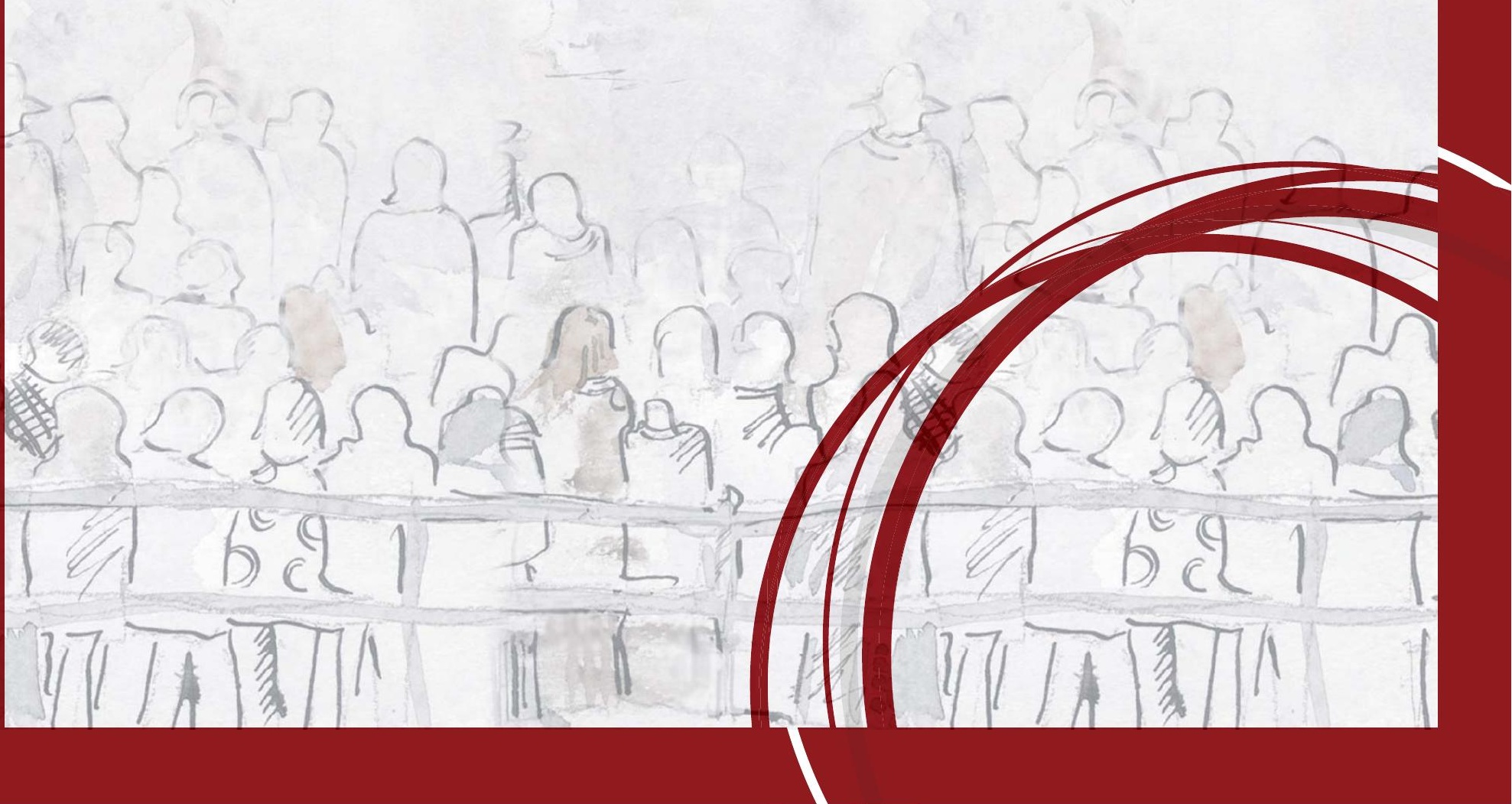


THE EFFECT OF UNEMPLOYMENT BENEFIT

GENEROSITY ON UNEMPLOYMENT DURATI ON:

QUASI - EXPERI MENTAL EVI DENCE FROM SLOVENIA

CELSI Discussion Paper No. 37

J anuary 2016

\section{Matija Vodopivec}

International School for Social and Business Studies

\section{Suzana Laporšek}

University of Primorska

\section{Primož Dolenc}

University of Primorska

\section{Milan Vodopivec}

University of Primorska, International School for Social and Business Studies, I ZA

The Central European Labour Studies Institute (CELSI) takes no institutional policy positions. Any opinions or policy positions contained in this Discussion paper are those of the author(s), and not those of the Institute.

The Central European Labour Studies Institute (CELSI) is a non-profit research institute based in Bratislava, Slovakia. It fosters multidisciplinary research about the functioning of I abour markets and institutions, work and organizations, business and society, and ethnicity and migration in the economic, social, and political life of modern societies.

CELSI Discussion Paper series is a fIagship of CELSI's academic endeavors. Its objective is the dissemination of fresh state-of-the-art knowledge, cross- fertilization of knowledge and ideas, and promotion of interdisciplinary dialogue about l abour markets or broader labour issues in Central and Eastern Europe. Contributions fromall social science disciplines, including but not limited to economics, sociology, political science, public polic social anthropology, human geography, demography, l aw and social psychology, are welcome. The papers are downloadable from http:/l www. celsi.sk. The copyright stays with the authors.

\section{Central European Labour Studies Institute (CELSI)}


CELSI Discussion Paper No. 37

J anuary 2016

\section{ABSTRACT}

\section{The Effect of Unemployment Benefit Generosity on Unemployment Duration: Quasi-experimental Evidence from Slovenia}

The paper analyses the effects of a 2011 increase in the unemployment benefit replacement rate on the job-finding rate of slovenian benefit recipients. Using registry data on the universe of slovenian unemployment benefit recipients, we exploit legislative changes that selectively increased the replacement rates for certain groups of workers while leaving them unchanged for others. Applying this quasi-experimental approach, we find that increasing the replacement rate significantly decreases the hazard rate of the transition from unemployment to employment, with an implied elasticity of the hazard rate with respect to benefit replacement rate being 0.7 to 0.9 . The results also show that increase of the unemployment benefit replacement rate does not affect the job-finding probability of jobseekers whose reason for unemployment is employer exit, and that the effects of the increase of replacement rate are present only upon exit to employment and not to inactivity.

JEL Classification: J64, J65

\section{Corresponding Author:}

Mat i ja Vodopi vec

International School for Social and Business studies

Mari borska cesta 7, 3000 Celje, slovenia

Emai I: matija.vodopivec@mfdps.si

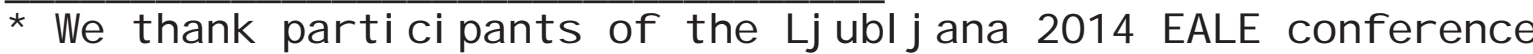
and 2013 IZA Summer School for their comments on the paper. 


\section{Introduction}

In January 2011 Slovenia increased the generosity of its unemployment insurance (UI) system by increasing the replacement rate in the initial period of benefit receipt. ${ }^{1}$ Previously, the replacement rate was 70 percent in the first three months of unemployment, and the new law increased this rate to 80 percent. After the first three months of unemployment, the replacement rate decreases to 60 percent, which was the case both before and after the new law went into effect.

A cursory look at the survival functions for recipients of unemployment benefit (UB) under the old and new law suggests that higher benefit generosity has, by and large, failed to slow down the job-finding rates of benefit recipients. Despite the increase in generosity under the new law, there is no discernible difference in the survival rate of recipients exiting from unemployment to employment in the first two months of unemployment under the new and the old law, and in the third month, the survival rate under the new law is even lower than under the old law (Figure 1). The divergence between the survival rates becomes progressively larger in subsequent months. That more generous benefits are associated with faster reemployment is counterintuitive and conflicts with the empirical studies of the changes of the UB level (see below). The result thus opens several questions, above all, are there other important factors or circumstances determining exit to employment that can explain this result, and whether more sophisticated methods that take these factors into account can help identifying the effects of the increase of UB generosity as well as demonstrating the underlying causality.

\footnotetext{
${ }^{1}$ The increase of unemployment benefits and the 2010 dramatic increase of the minimum wage was part of the labor market reform package of the government. The "bitter" part of the reforms - the relaxation of the Labor Code - failed to materialize until 2013 (and it was introduced by a successive government).
} 
In theory, the increase of generosity of UB may create disincentive effects but through the so-called entitlement effect it may also work in the opposite direction. That an increase in the UB reduces the recipient's probability of transition from unemployment to employment follows from job-search models (the reservation wage is assumed to rise with the benefit level), as well as from simple labor supply models (because the presence of unemployment insurance modifies the budget constraint - less income is forgone by staying unemployed, and a utility maximizing individual chooses a longer duration of unemployment). Search theory also implies that the reservation wage declines and the exit rate increases as one nears the date of expiration of the benefits. ${ }^{2}$ However, the entitlement effect - deriving from the recognition that by taking employment one requalifies for UBs - may make the transition to employment more attractive, not less, particularly close to the benefit exhaustion date.

Although theoretical models come with opposing predictions, empirical studies of the increase of UB generosity clearly demonstrate negative effects of increased level of UBs. Particularly persuasive are newer studies that exploit difference-in-differences or regression discontinuity methodology. For example, Carling et al. (2001) document that following a decrease in UI benefits in Sweden, outflow from unemployment increased considerably (with an implied elasticity of unemployment duration relative to benefits of 1.6). In their analysis of Austrian claimants, Lalive et al. (2006) find that increasing the replacement rate reduced the probability of exit from unemployment, but with much smaller elasticity of 0.4 (they find stronger disincentive effects from

\footnotetext{
${ }^{2}$ There are three types of effects implied by Mortensen's seminal paper (1977). First, for qualified unemployed workers the exit rate increases as they approach benefit expiration. Second, a rise in benefits reduces the exit rate for insured workers who have recently become unemployed, and increases the exit rate for insured workers who are close to benefit expiration. This follows from the fact that a higher benefit level increases both the value of continued search as unemployed and the value of accepting an offer. The immediate value of higher benefits is small for workers close to benefit exhaustion, because they are in a similar situation as workers not qualified for the benefit. And third, a rise in benefits increases the exit rate for unemployed workers who are not qualified (the entitlement effect).
} 
increasing the maximum duration of benefits). Uusitalo and Verho (2010) also find disincentive effects of the increase of the UB level for Finland, with a 15 percent increase in the UI benefit level extending time until re-employment by 12 percent (implying an elasticity of 0.8$).^{3}$

The purpose of the paper is to rigorously evaluate the effects of the 2011 increase in the UB replacement rate on job-finding rate of benefit recipients. It uses rich administrative database of all UB recipients and takes advantage of the quasiexperimental nature of the legislative change - the fact that for a specific group of workers, the benefit level remained unchanged - in trying to identify the effects of the new law via difference-in-differences method. The paper thus compares the difference in job-finding probability before and after the change for the group affected by benefit increase - the treatment group, with the difference in job-finding probability before and after the legislative change for the group of jobseekers not affected - the control group. In doing so, it controls for macroeconomic effects, as well as for composition effects, that is, for changes in characteristics of UB recipients. The advantage of the quasi-experimental setting is the ability to attribute observed changes in job finding to legislative changes, that is, to pinpoint the underlying relationship in a causal manner.

The results invalidate the "naked eye" perspective of the effects of the new law as captured in the survival function depiction. The difference-in-differences results show strong negative effect of the increase of the replacement rate on the hazard rate of the transition from unemployment to employment, with the implied elasticity of the hazard rate with respect to benefit replacement rate being 0.7 to 0.9 . The results also show that the increase of UB replacement rate does not affect job-finding probability of jobseekers whose reason for unemployment is employer exit, and that the effects of the

\footnotetext{
${ }^{3}$ The empirical evidence on the disincentive effects of the other key UB design parameter, the potential benefit duration, is also well established, although the precise magnitude of its effects varies across countries (for a recent survey, see Tatsiramos and van Ours, 2014).
} 
increase of UB replacement rate are present only upon exit to employment and not to inactivity.

By focusing on the effects of the increase in the replacement rate on the hazard of exiting unemployment, this paper adds to the findings on the effects of UI in Slovenia. Early related research on Slovenia examined determinants of exit from covered unemployment (Vodopivec, 1995). In one of the papers that persuasively document causality, van Ours and Vodopivec (2006) find that decreasing the potential benefit duration $(\mathrm{PBD})$ in Slovenia in the late 1990s strongly increased the hazard rate for exiting unemployment to employment. At the same time, van Ours and Vodopivec (2008) show that the resulting re-employment outcomes (duration of employment, level of wages, and type of employment) were not affected by the shortened duration of unemployment.

The structure of the paper is as follows. We first present the Slovenian UI program and describe how legislative changes in Slovenia enacted at the beginning of 2011 facilitate the identification of the effects of these changes on job finding. We then describe the registry data and the methodology used in the study. In the results section, we present estimates of the Cox proportional hazard rate models for exit from unemployment among UB recipients. The final section concludes with some policy implications.

\section{Changes introduced by the $2011 \mathrm{UI}$ law}

Slovenia has a UI program that is broadly similar to those in other European countries. The program is mandatory for all formal sector workers (except for the self-employed). Unemployed workers qualify for benefits following involuntary termination from indefinite employment contracts or after the conclusion of fixed-term employment contracts. Benefits are earnings related, determined as a fraction of the wage associated 
with the job preceding unemployment, that is, by the replacement rate, and subject to an absolute minimum and maximum in nominal terms. The duration of benefit entitlement is determined by the cumulative duration of employment engagements preceding the onset of unemployment and it ranges from a minimum of three months up to a maximum of 25 months.

In January 2011, Slovenia introduced a new law that increased the generosity of its UI program. Arguably the most significant change was the increase of the replacement rate in the first three months of benefit entitlement. Previously, the replacement rate had been 70 percent in the first three months of unemployment, and the new law increased this rate to 80 percent. After the first three months, the replacement rate decreases to 60 percent, which is the case both under the old and the new law. In addition, the new law increased both the minimum and maximum level of benefits. Under the old law, the UB may not be lower than 45.56 percent of the minimum wage and not higher than three times this amount. The new law set absolute minimum and maximum benefit level in EUR terms - the UBs may not be lower than 350 EUR and not higher than 1,050 EUR. ${ }^{4}$ The new law also slightly eased access to benefits for young workers and workers with short periods of work experience, and marginally changed PBDs for older workers.

Identification of causal effects of the legislation change is facilitated by a special feature of the change of the 2010 UI law that creates a quasi-experimental setting, thus allowing the use of difference-in-differences method. While the 2011 law increased the replacement rate in the first three months of benefit receipt, the benefit level remained unchanged for high-pay workers - for those whose wage before becoming unemployed exceeded 1,313 EUR (for them, the maximum benefit amount was binding). This group

\footnotetext{
${ }^{4}$ The gross minimum wage in January 2011 was 748.10 EUR. Under the old law, the minimum benefit level would therefore amount to 340.83 EUR, and the maximum amount to 1022.49 EUR.
} 
thus forms a natural control group, with other jobseekers forming the treatment group (the group for whom the replacement rate changed). The formation of treatment and control groups allows the use of a difference-in-differences method of identification of the effects of the benefit level increase as described below.

\section{Data and methodology}

The paper uses rich administrative data on jobseekers - UB recipients to estimate jobfinding rate models of exit from unemployment. Below we describe the data and provide details about the methodological approach, including identification strategy of the effects of the increase of replacement rate.

\section{Data and definition of dependent variable}

The data used in this study consists of registry data covering all unemployment spells from January 2010 to December 2012 in Slovenia. ${ }^{5}$ For each individual unemployment spell, the register contains the following information:

- starting date of unemployment,

- reason for onset of unemployment,

- date of employment or censoring due to sickness, if applicable,

- potential benefit duration (PBD) and level of UBs, if applicable,

- wage at previous job (basis for calculating UBs), if applicable, and

- personal demographic characteristics (age, education, gender, region).

\footnotetext{
${ }^{5}$ The source of the data are two databases from the government agency tasked with administering the UI program, the Employment Service of Slovenia (ESS). The first database, the registry of unemployed individuals, covers individuals who are registered as unemployed and who may not necessarily be receiving benefits. The second database covers UB recipients. Individuals who are not recipients of UBs may register at the ESS because it provides job placement and training services; in addition, being listed in registry is a precondition for receiving certain categories of social assistance payments.
} 
The final dataset consists of a total number of 37,905 jobseekers - recipients of UB, of whom 5.7 percent were included in the control and the rest in the treatment group. Summary statistics of key variables are provided in Table 1, for all jobseekers and separately for treatment and control groups (structure by gender, age and education, and work history). Note that the shares of beneficiaries before and after the legislative change are quite similar, for both treatment and control groups.

Defining when individuals are "at risk of employment" and when they are censored is based on an elaborate set of eligibility criteria. The onset of risk is defined as the beginning of unemployment; this does not necessarily coincide with the date of registration at the Employment Office because UB claimants are entitled to full benefits if they apply up to one month after the onset of unemployment (the median difference between the application date and date of unemployment is 4 days). Individuals are presumed to be at risk so long as they are registered as unemployed. Censoring occurs for the duration of sick or maternity leave or during periods of declared vacation days (UB recipients are entitled to a basic number of vacation days). For the following events, individuals are no longer under observation and are presumed to be censored (in addition, such individuals are no longer eligible for UBs): unavailability of unemployed individuals to employment office staff trying to check their unemployment status, not actively seeking formal employment, retirement, rejection of job offers, fulltime enrollment in an educational institution, voluntary suspension of unemployment status, and emigration to a foreign country.

Exiting to employment is defined as exiting to either full-time employment or entering public works programs. Unemployed individuals who gain part-time employment are entitled to benefits that are proportional to the number of hours that they are lacking 
to full-time employment, and are still considered to be at risk (i.e., unemployed). ${ }^{6}$ Individuals' eligibility for UBs is suspended for the duration of their engagement in public works, although individuals may automatically receive UBs at the conclusion of such engagements (such instances are construed as the beginning of a new unemployment spell). Exiting to full-time employment includes becoming selfemployed. It is worth noting that in our analysis, time is measured in days, as both the starting and ending dates of the unemployment status of individuals are determined precisely by administrative procedures - registration and withdrawal as recorded by the Employment Office.

\section{Estimation methodology and identification strategy of the legislative change effects}

The paper estimates semi-parametric hazard rate models of exit from unemployment to employment that is a standard econometric approach in modeling exit from unemployment based on micro data. Competing risk models, accounting for exits both to employment and inactivity, are also estimated. To be able to identify the effects of the law that increased the replacement rate of UBs, the paper deploys the differencein-differences methodology, exploiting the fact that for one group of benefit recipients - highly paid workers - the replacement rate stayed unchanged. Below we describe the methodology in greater detail.

Speaking formally, we define $D \in\{0,1\}$ as the treatment operator equal to 1 if an individual receives treatment (i.e., is subject to an increase in the replacement rate) and zero otherwise. Let $Y(1)$ denote the treated outcome and $Y(0)$ denote the nontreated outcome. Additionally, let $Y_{t}$ and $Y_{t+1}$ denote the outcomes prior to and after

\footnotetext{
${ }^{6}$ In estimates of the hazard functions, a time-varying covariate denoting the degree of part-time employment is included in the model to allow for a potentially different hazard rate for exiting to employment.
} 
the legislative change, respectively. The difference-in-differences estimator $\theta_{\text {did }}$ is then given by

$$
\theta_{D i D}=\left(E\left[Y_{t+1}(1) \mid D=1\right]-E\left[Y_{t}(0) \mid D=1\right]\right)-\left(E\left[Y_{t+1}(0) \mid D=0\right]-E\left[Y_{t}(0) \mid D=0\right]\right)
$$

In order for the estimator $\theta_{\text {did }}$ to provide an unbiased and consistent estimate of the average treatment effect in panel data, two assumptions must hold. First, the control and treatment groups must be subject to equal time trends - in this case, the underlying macroeconomic time trends must have affected the treatment and control groups equally. Secondly, treatment effects must be homogenous - i.e., the replacement rate increase must have impacted those in the treatment group in the same manner that a (counterfactual) increase would have affected the control group. Under these conditions,

$$
\theta_{D i D}=E\left[Y_{t+1}(1)-Y_{t+1}(0)\right]
$$

so that the difference-in-differences estimator $\theta_{\text {did }}$ is an unbiased and consistent estimate of the average treatment effect.

We empirically determine treatment effects by estimating a Cox proportional hazard model of exit from unemployment to employment with the following specification:

$$
\lambda(\mathrm{t} \mid T, L, I, X)=\lambda_{0}(\mathrm{t}) \cdot e^{\alpha T+\beta L+\gamma I+\delta^{\prime} X}
$$


where $\lambda_{0}(\mathrm{t})$ denotes the non-parametric baseline hazard, $T$ is a binary variable equal to 1 for those who became unemployed in $2011, L$ is a binary variable equal to 1 for those who were affected by the policy change, and $I$ is an binary interaction variable of $L$ and $T$ that captures the specific effects of the policy change on the treatment group. $\boldsymbol{X}$ is a vector of control variables (see below); $\alpha, \beta, \gamma$ and $\delta$ pertain to coefficients that are to be estimated. We also apply hazard rate models extended to competing risk models that explicitly cover both exits to employment and inactivity.

In the above set-up, the difference-in-differences method helps to isolate the effect of the legislative change as follows. We first calculate baseline hazard rates for exit from unemployment before and after the legislative changes using a control group comprised of individuals whose replacement rate remained unchanged. These are used to establish a baseline for comparison and are assumed to account for period-specific effects, such as changes in the macroeconomic environment that could affect the job-finding rate. We then calculate "before and after" hazard rates for the group for which replacement rate increased. Comparing the differences in the changes of the hazard rates between treatment and control groups before and after the law change thus yields the effect of the legislative change. As mentioned above, identification of causal effects of the legislation change is enabled by a special feature of the change of the 2010 UI law that creates a quasi-experimental setting: the law increased the replacement rate in the first three months of benefit receipt for all except for high-pay workers, thus singling them out as a natural control group.

To help isolate the effects of the change of the law, we control for the following factors that affect job-finding, above all, for changes in the composition of UB recipients and in the macroeconomic environment. For that purpose, the following variables are included as control variables (in the form of categorical variables): 
- Potential benefit duration (PBD), reflecting possible strategic behavior on the part of jobseekers related to the duration of the benefit receipt). ${ }^{7}$

- Whether reason for unemployment is employer exit (either bankruptcy or liquidation) or other reasons. Because our analysis revealed important behavioral differences between these two groups of jobseekers, this variable also served to perform separate of model estimation for these two groups of recipients (see below).

- Duration of work experience

- Personal characteristics (gender, age and education)

- Monthly dummies to account for seasonal effects affecting the composition of inflows to unemployment or seasonal variation in demand for jobseekers.

\section{Checking the suitability of the control group}

A necessary condition for a valid interpretation of the difference-in-differences coefficient as the treatment effect - the causal effect increase in the replacement rate - is that individuals have "imprecise" control over the assignment variable (Lee \& Lemieux, 2010). In our case, the relevant question is whether individuals close to the wage cutoff can manipulate their placement either below or above the threshold relevant for assignment (1,434 EUR and 1,313 EUR prior to and after the legislative change, respectively). For several reasons, we believe the answer is no. Firstly, on a theoretical level, for individuals to have a higher replacement rate and fall under the treatment group, their average monthly wages in the preceding eight months must fall below the relevant threshold. However, there is no financial incentive for the individual to seek a lower wage in the period prior to unemployment, because the maximum

\footnotetext{
${ }^{7}$ The presence of disincentives in leaving unemployment associated with the length of PBD among Slovenian UB claimants - the topic not covered in the present paper - have been studied by van Ours and Vodopivec (2006).
} 
benefit is fixed for all individuals above the relevant threshold. Secondly, an empirical analysis of the wage distribution shows no discontinuities around the threshold (Figure 2), a fact also suggesting the absence of wage manipulation.

The precise formation of treatment and control groups is guided by the following considerations. First, in an attempt to avoid non-random sample selection stemming from strategic behavior of UB recipients, we exclude unemployment spells that begin immediately preceding and immediately following the change in the legislation. Although eligibility for UBs is conditional on non-voluntary termination of employment (i.e., quitters are not eligible for UBs), the patterns of inflows to unemployment in December 2010 and January 2011 are indicative of strategic behavior on the part of claimants. During the period just before the introduction of the new legislation the pending increase in the UBs generosity gave individuals an incentive to delay their unemployment claims, and indeed the inflow to registered unemployment in January 2011 was exceptional large - see Figure 3. The figure also shows that the unemployment inflow was abnormally large also in December 2010, the reason being the pending change in old age legislation (see below). For this reason, we exclude unemployment spells beginning in December 2010 or January 2011 (such an approach is also used by van Ours and Vodopivec (2006) in their analysis of Slovenian unemployment registry data). Second, we experiment with various levels of the nominal wage thresholds that are used for formation of the control group.

We impose an age limitation on the jobseekers considered in the analysis. In addition to the change in legislation concerning the UBs generosity, significant reforms to the pension system were due to take effect in Slovenia beginning in January 2011. In expectation of these reforms, individuals close to fulfilling retirement criteria had an incentive to retire under the existing legislation, which offered more generous conditions for retirement (in the end, the proposed pension reform was retroactively struck down 
in a referendum). To avoid unemployment spells that may have been affected by strategic behavior in handling retirement, we exclude from the analysis male jobseekers older than 55 years, and female jobseekers older than 50 years.

\section{Results}

As mentioned above, the "naked eye" perspective - the comparison of survival functions of UB recipients before and after the introduction of the more generous UI law - does not support a prior that more generous benefits are associated with lower job-finding rate. Using methodology described above, we performed a more comprehensive and sophisticated analysis that did produce the hypothesized results.

Table 2 presents the results from a Cox proportional hazards model for the first three months of benefit receipt for the groups of recipients described above. As dictated by the difference-in-differences approach, the estimated models cover the period before and after the introduction of the new law and include groups of recipients affected and unaffected by the law. The estimation controls for various sets of factors that affect job-finding rate, including personal and work history characteristics of beneficiaries, as well as, through the PBD, the design of UB system. We also control for changes in macroeconomic environment (such as change in business climate) and for seasonal variations in job-finding chances by including yearly and monthly dummies. Various models are presented, reflecting different definitions of control and treatment groups, selections of subsamples, and approaches (single and competing risk models).

The results obtained in a quasi-experimental set-up and after controlling for composition and macroeconomic effects show a significant negative effect of higher benefit generosity on job-finding rate. The key parameter of interest - the parameter capturing the difference-in-differences effect, that is, the estimated effect of the increase in the replacement rate - shows that, in comparison to control group, the job-finding 
probability of beneficiaries in the treatment group significantly worsened during the period when they received benefits under the higher replacement rate. The parameter estimates of different specifications (estimated on the whole sample, that is, models (1) to (3)) are in the similar range, varying from 0.874 to 0.895 , indicating a 10.5 to 12.6 percent lower hazard rate for exiting unemployment attributable to higher UB replacement rate. The implied elasticity of the hazard rate with respect to benefits, associated with the 14.3 percent increase in the replacement rate (the increase from 70 to 80 percent), is thus in the range between 0.73 to 0.88 . The estimated parameters are robust to alternate definitions of control and treatment groups based on varying thresholds for pre-unemployment wages (models (1) to (3)), so we retained the specification dubbed "Baseline" in Table 2 for further analysis. ${ }^{8}$

Estimated hazard rate models also confirm that the chosen control group is a suitable comparator. The estimated relative hazard rate for the treatment group shows that this group faces, on average, 9 to 11 percent smaller chances for reemployment than the control group, supporting the assumption that the two groups are reasonably well comparable. Interestingly, the estimation results show that starting to collect UB in 2011 is associated with lower probability of job finding (although the year effect is statistically significant only in model (2)). This result is at odds with the notion that macroeconomic conditions improved in 2011 that could be obtained based on simple comparison of survival functions for 2010 and 2011.

The results of the estimated models also show that treatment effects vary for different groups of job-seekers. In particular, separate estimation of models for the group of beneficiaries whose reason for unemployment is employer exit (either bankruptcy or liquidation) and for a group who became unemployed for other reasons shows a

\footnotetext{
${ }^{8}$ As discussed by Lee and Lemieux (2010), varying the estimation range relative to the cut-off point is a way to verify whether the estimated effects are non-linear over the whole range of the forcing variable (in our case, the level of pre-unemployment wages).
} 
significant negative effect of the increased UB replacement rate for the latter and insignificant effect for the former group (models (4) and (5)). According to model (4) showing results for jobseekers unemployed for other reasons than employer exit, the estimated effect of the increase of replacement rate - 17.5 percent lower hazard rate for exiting unemployment attributable to higher UB replacement rate - is even larger that in models (1) to (3).

Our interpretation of this result is that on average, UB recipients whose reason for unemployment is employer exit face better reemployment chances, which makes them less susceptible to changes of UB design. First, in contrast to individual layoffs, during which firms lay off underperforming or less desirable workers (see, for example, Galuscak et al., 2012), bankruptcies indiscriminately affect all workers. Because of the non-selective nature of separations, the UB recipients who are unemployed due to bankruptcies are likely to be higher-caliber job-seekers possessing more valuable unobserved characteristics such as work motivation and ability to collaborate in teams than their counterparts who are unemployed for other reasons (these two groups may also differ in their observable personal characteristics, but these differences are accounted for in estimated models).

Second, better reemployment chances among recipients whose reason for unemployment is employer exit stem also from the fact that many of the workers who lost jobs due to employer bankruptcies found jobs in new, smaller firms in the same industry that sprouted after the demise of some large, unviable enterprises (particularly prominent case is construction - the "Great Recession" did away with all large construction firms in Slovenia). We thus interpret the insensitivity of the employment hazard rate of these recipients to the increase of the UB replacement rate as the consequence of their better job-finding opportunities. 
To put the strength of the effects of the change of the UB replacement rate in perspective, we compare them to the effects of benefit exhaustion. That is, we compare the "spike" effects in the hazard rate of exit to employment produced by the reduction of the replacement rate at the end of third month of UB receipt from 80 to 70 percent to the effects of the exhaustion of the right to UB (transition from "covered" to "uncovered" unemployment) - Figure 4. The comparison suggests that the quantitatively, the effects of benefit exhaustion are larger than the effects of the reduction of the replacement rate. This result is in line with the conclusion of Tatsiramos and van Ours (2014) that changes in duration of benefits lead to stronger effects compared to changes in benefit level. Of course, these results may well be colored by the country's UB system design (primarily by the level and potential duration of benefits).

Other results show that another variable associated with incentive effects of the UB design - potential benefit duration (PBD) - is shown to be negatively associated with job-finding probability. In comparison to the baseline group consisting of jobseekers with three months of PBD, groups of workers with longer PBD have systematically lower job-finding probabilities, with the difference ranging from 19 to 20 percent for the group with 6 month PBD to $66-68$ percent for the group with 24 or 25 month PBD. While it is safe to assume that groups with longer PBD face more difficulties in finding a job because they are older, the fact that age is controlled for separately (although the parameter estimates of age groups are mostly statistically insignificant) may indicate of the presence of disincentives associated with the receipt of UB.

Parameters of control variables included in the job-finding rate models are also of interest. Men are observed to have a 5 percent lower job-finding rate as women hazard rate relative to women (the difference is statistically significant except in model (1)). 
This result stands in contrast to the findings of van Ours and Vodopivec (2006), who document higher hazard rates for exiting from unemployment for men. One possible explanation for this finding is that Slovenia's weak economic environment has had a disproportionally adverse impact on traditionally male-dominated fields such as construction. Older workers have lower hazard rates for exiting unemployment, although the results show statistically significant negative effects only for the oldest group (those above 50 years old). Interestingly, higher levels of education are not definitively associated with increased hazard rates of exit from unemployment: the largest hazard rate is for individuals with completed technical secondary education.

The competing risk analysis shows that the effects of the rise of UB replacement rate are present only for beneficiaries exiting to employment, not to inactivity. The difference-in-differences results show that the increase of the UB replacement rate reduced the hazard rate for those exiting to employment by 17.8 percent, but that it did not affect the hazard rate for exiting to inactivity - the estimated parameter is insignificant (Table 3). One explanation for this finding is that when exiting from covered unemployment to inactivity, the increased replacement ratio does not change much the relevant trade-offs as such persons are likely to be led by non-monetary considerations. One other interesting result is that men are not less likely than women to exit to inactivity.

\section{Conclusion}

Exploiting legislative changes that enable a quasi-experimental approach and using registry data on the universe of Slovenia's UB recipients, we find that the 2011 increase in UB replacement rate during the first three months of benefit collection decreased the hazard rate for exiting unemployment. The implied elasticity of the hazard rate of exit to employment with respect to UB replacement rate is 0.7 to 0.9 . Interestingly, we 
also find that the increase of UB replacement rate does not affect the probability of exit to inactivity, nor does it affect the job-finding probability of jobseekers whose reason for unemployment is employer exit.

What do the above findings suggest about the desired UB system design? Assuming that the moral hazard dominates the insurance function of the system, a declining schedule of benefits has been shown as optimal (Shavell and Weiss, 1979; Hopenhayn and Nicolini, 1997). But allowing for the ability to borrow and save on the part of jobseekers, the optimal policy is a constant benefit level (Shimer and Werning, 2008) - or, taking into account individual's wealth level, increasing (Rendahl, 2012). ${ }^{9}$ Indeed, Kolsrud et al. (2015) find that the moral hazard cost of benefits is larger when paid earlier in the spell, and that the insurance value of benefits increases throughout the spell. While further research is needed to gauge the relative importance of moral hazard and insurance function of UB in Slovenia, the results of our paper may well suggest that the 2011 legislative changes have gone in wrong direction and that making the benefit schedule more flat or even introducing an increasing benefit schedule would have been welfare increasing.

\footnotetext{
${ }^{9}$ The optimal schedule of UB depends on a variety of factors and assumptions (among others, on assumptions about job search intensity, access to credit, heterogeneity of workers, and depreciation of human capital and arrival of job offers while staying unemployed) and is subject of a large literature (for a recent overviews, see Tatsiramos and van Ours, 2014).
} 


\section{References}

Carling, K., Holmlund, B., and Vejsiu, A. (2001). "Do Benefit Cuts Boost Job Findings? Swedish Evidence from the 1990s." Economic Journal,111: 766-790.

Galuscak, K., Keeney, M., Nicolitsas, D., Smets, F., Strzelecki, P., and Vodopivec, M. (2012). "The Determination of Wages of Newly Hired Employees: Survey Evidence on Internal Versus External Factors." Labour Economics, 19(5): 802-812.

Hopenhayn, H., and Nicolini, J.B. (1997). "Optimal Unemployment Insurance." Journal of Political Economy, 105: 412-438.

Kolsrud, J., Landais, C., Nilsson, P., and Spinnewijn, J. (2015). "The Optimal Timing of Unemployment Benefits: Theory and Evidence from Sweden." IZA Discussion Paper No. 9185.

Lalive, R., Van Ours, J., and Zweimüller, J. (2006). "How Changes in Financial Incentives Affect the Duration of Unemployment." Review of Economic Studies, 73(4): 1009-1038.

Lee, D. S., and T. Lemieux (2010). "Regression Discontinuity Designs in Economics." Journal of Economic Literature, 48(2): 281-355.

Mortensen, D. T., and Pissarides, C. A. (1999). "New Developments in Models of Search in the Labour Market." In Handbook of Labour Economics, Vol. 3B, pp. 25672627.

Rendahl, P. (2012). "Asset-Based Unemployment Insurance." International Economic Review, 53: 743-770.

Shavell, S., and Weiss, L. (1979). "The Optimal Payment on Unemployment Insurance Benefits over Time." Journal of Political Economy, 87: 1347-1362.

Shimer, R., and Werning, I. (2008). "Liquidity and Insurance for the Unemployed." American Economic Review, 98: 1922-1942.

Tatsiramos, K., and van Ours, J. C. (2014). "Labor Market Effects of Unemployment Insurance Design." Journal of Economic Surveys, 28(2): 284-311.

Uusitalo, R., and Verho, J. (2010). "The Effect of Unemployment Benefits on ReEmployment Rates: Evidence from the Finnish Unemployment Insurance Reform." Labour Economics, 17: 643-654. 
van Ours, J. C., and Vodopivec, M. (2006). "How Shortening the Potential Duration of Unemployment Benefits Affects the Duration of Unemployment: Evidence from a Natural Experiment." Journal of Labor Economics, 24(2): 351-350.

van Ours, J. C., and Vodopivec, M. (2008). "Does Reducing Unemployment Insurance Generosity Reduce Job Match Quality?“ Journal of Public Economics, 92: 684-695.

Vodopivec, M. (1995). "Unemployment Insurance and Duration of Unemployment: Evidence from Slovenia's Transition." The World Bank, Policy Research Working Paper No.1552. 
Figure 1: Kaplan-Meier survivor functions, old and new law

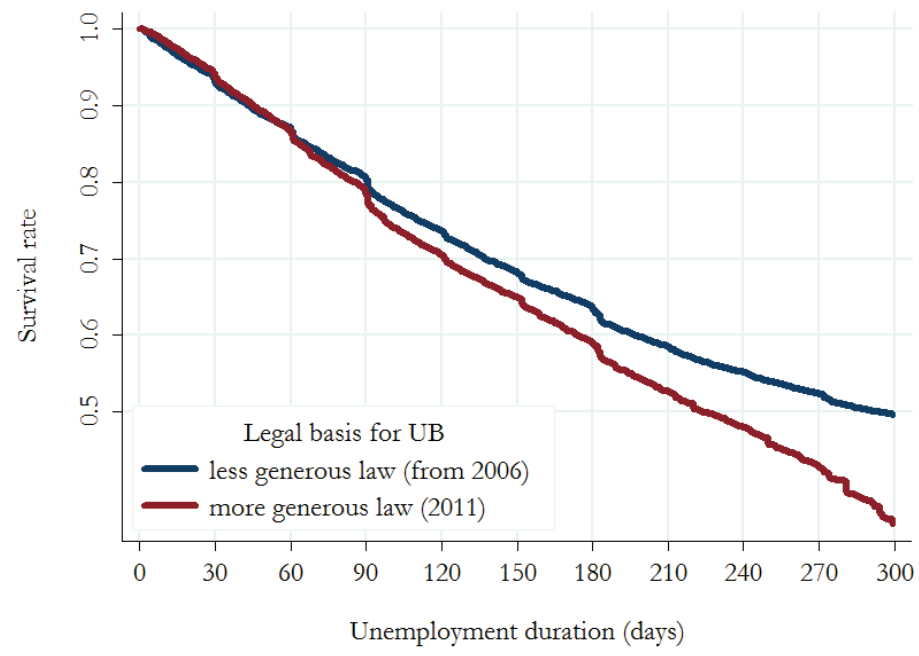

Note: Kaplan-Meier survival functions of individuals who were eligible for unemployment benefits at the onset of unemployment. Failure is defined as exiting to employment; other exits from unemployment registry database are construed as censoring. See data section for details.

Figure 2: Distribution of wages of UB recipients received in their preunemployment job, old and new law

Old law (less generous)

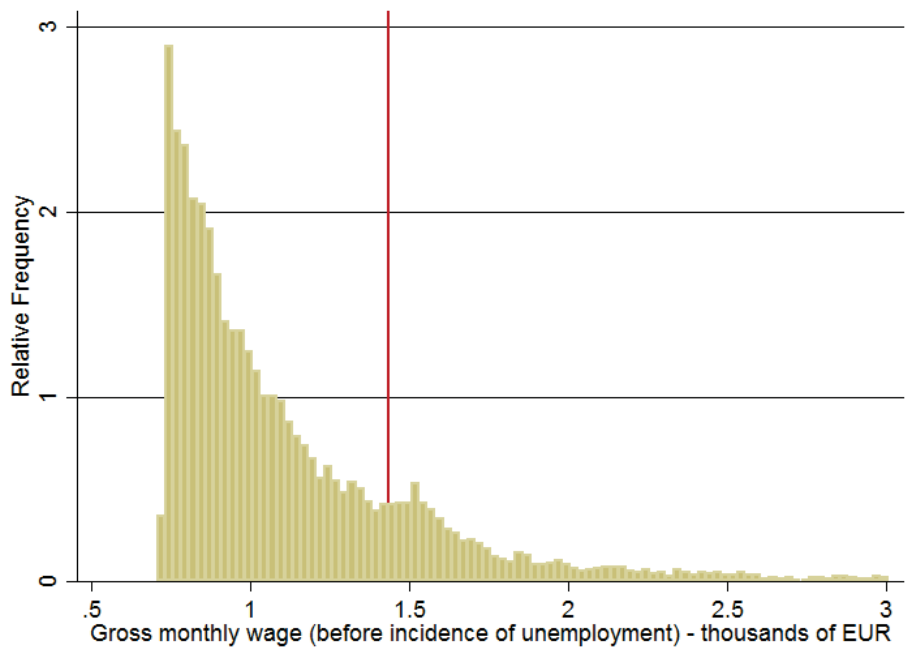

New law (more generous)

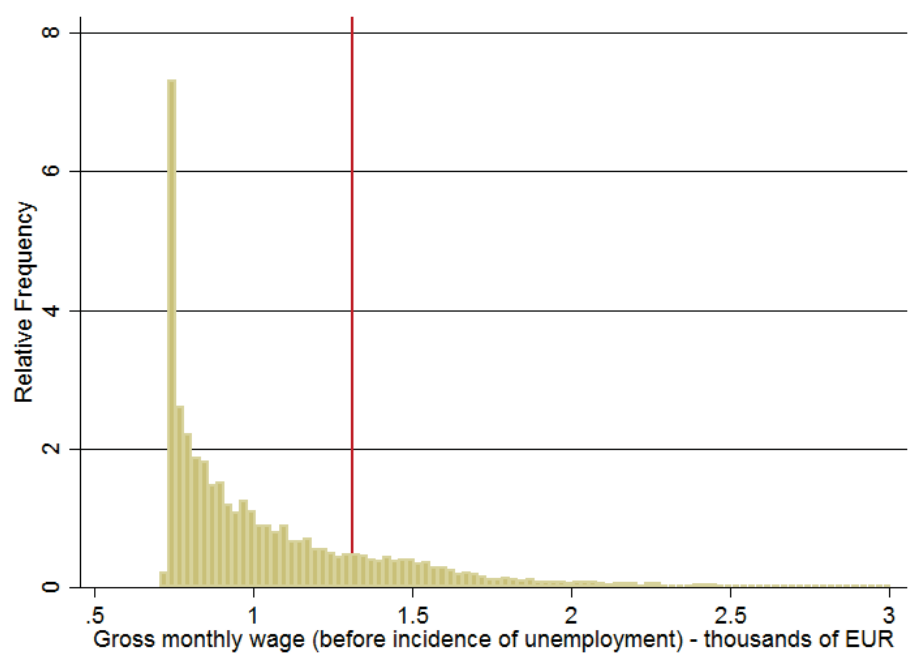

Notes: Vertical line denotes threshold for assignment into treatment or control group. 


\section{Figure 3: Monthly share of annual inflows into registered unemployment, 2009-2011}

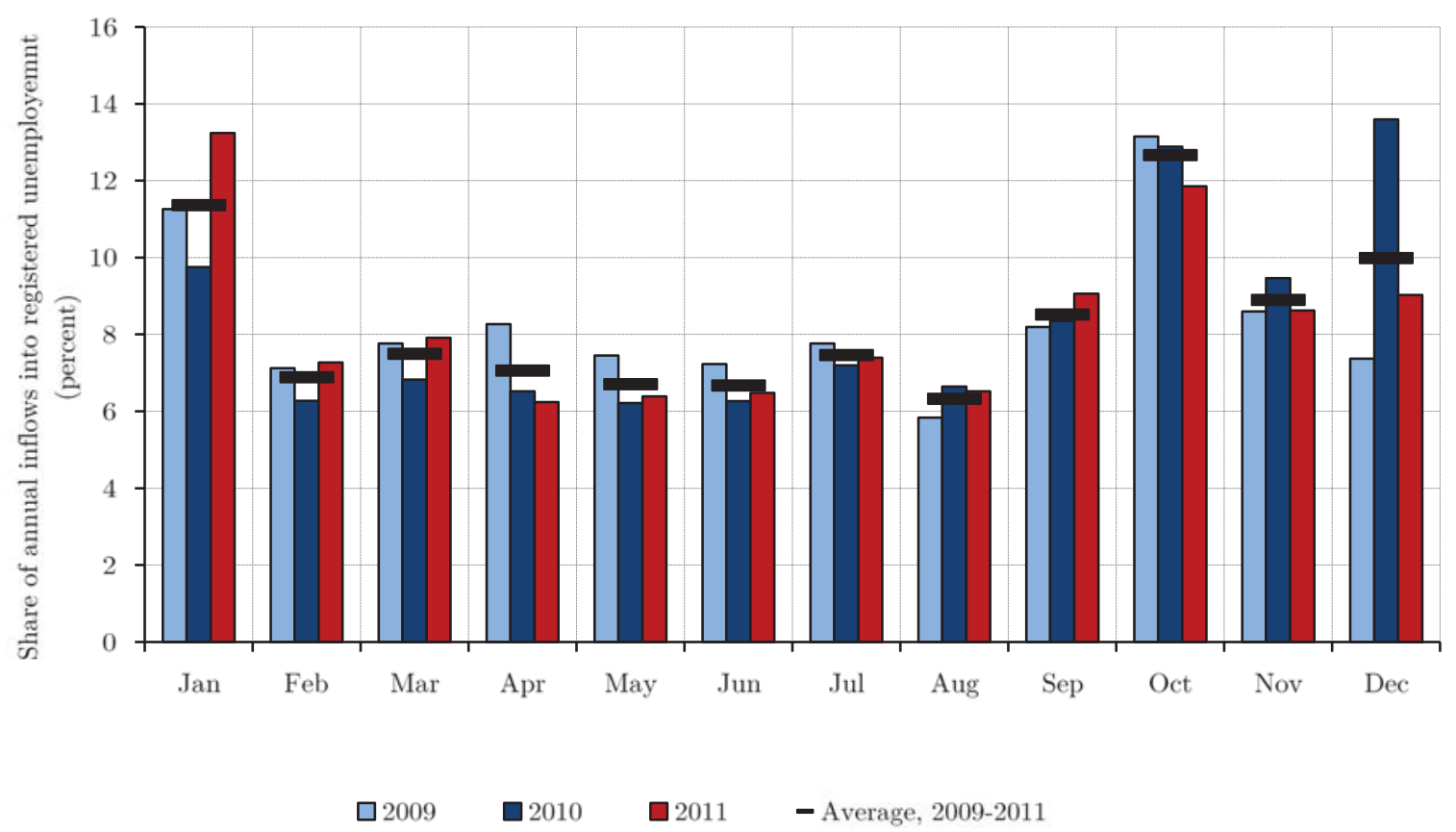

Notes: Monthly inflows into registered unemployment includes both individuals who are eligible for unemployment benefits and those who are not. Inflows for 2009 are included for reference purposes.

Figure 4: Spikes at benefit exhaustion and reduction

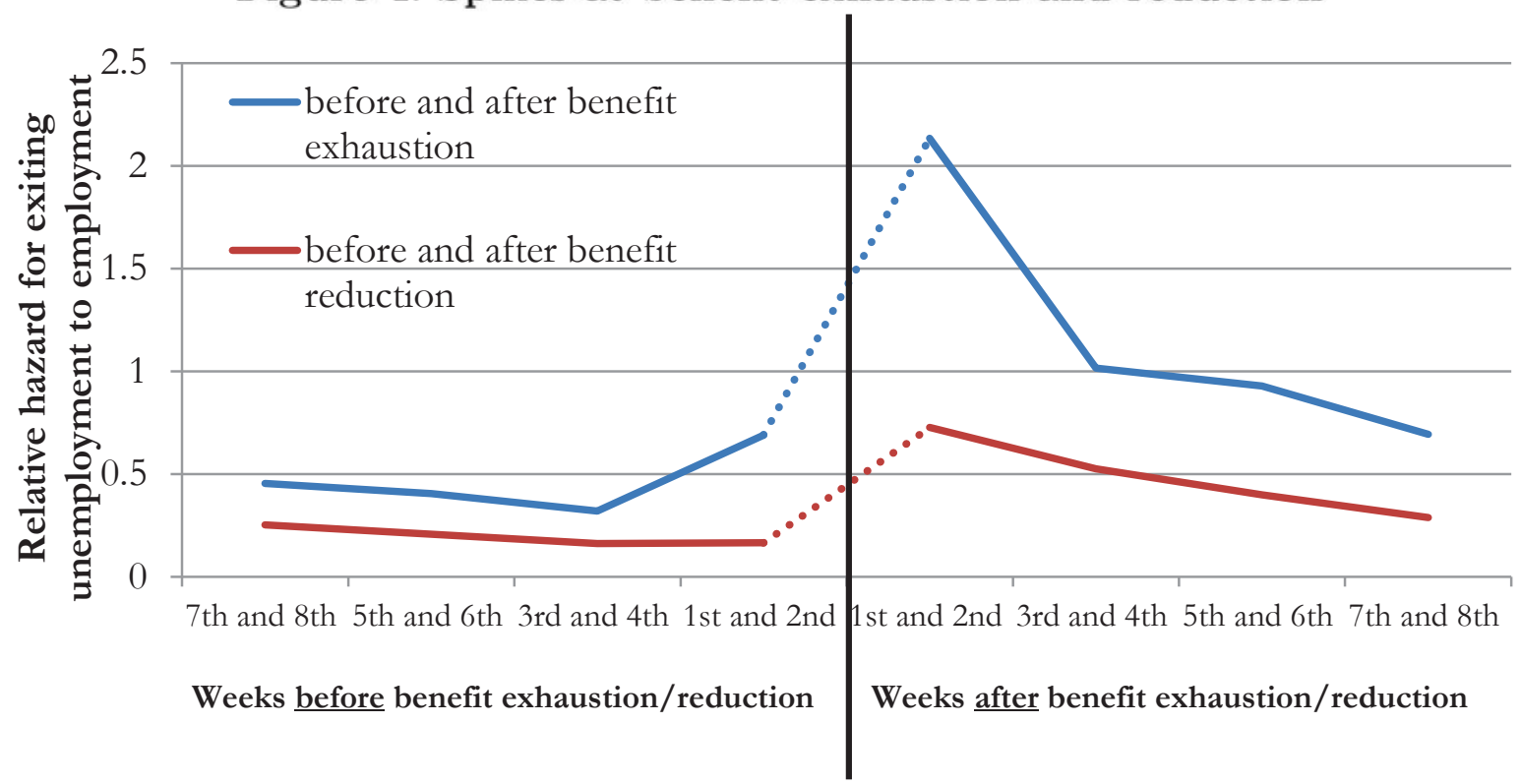

Note: The figure shows difference in the relative probability of exit from unemployment between jobseekers in the indicated week before or after benefit exhaustion and before and after benefit reduction, 
respectively, and the baseline group consisting of jobseekers in their third or higher month after the exhaustion of benefits (both the transition to employment and inactivity are treated as exits). 


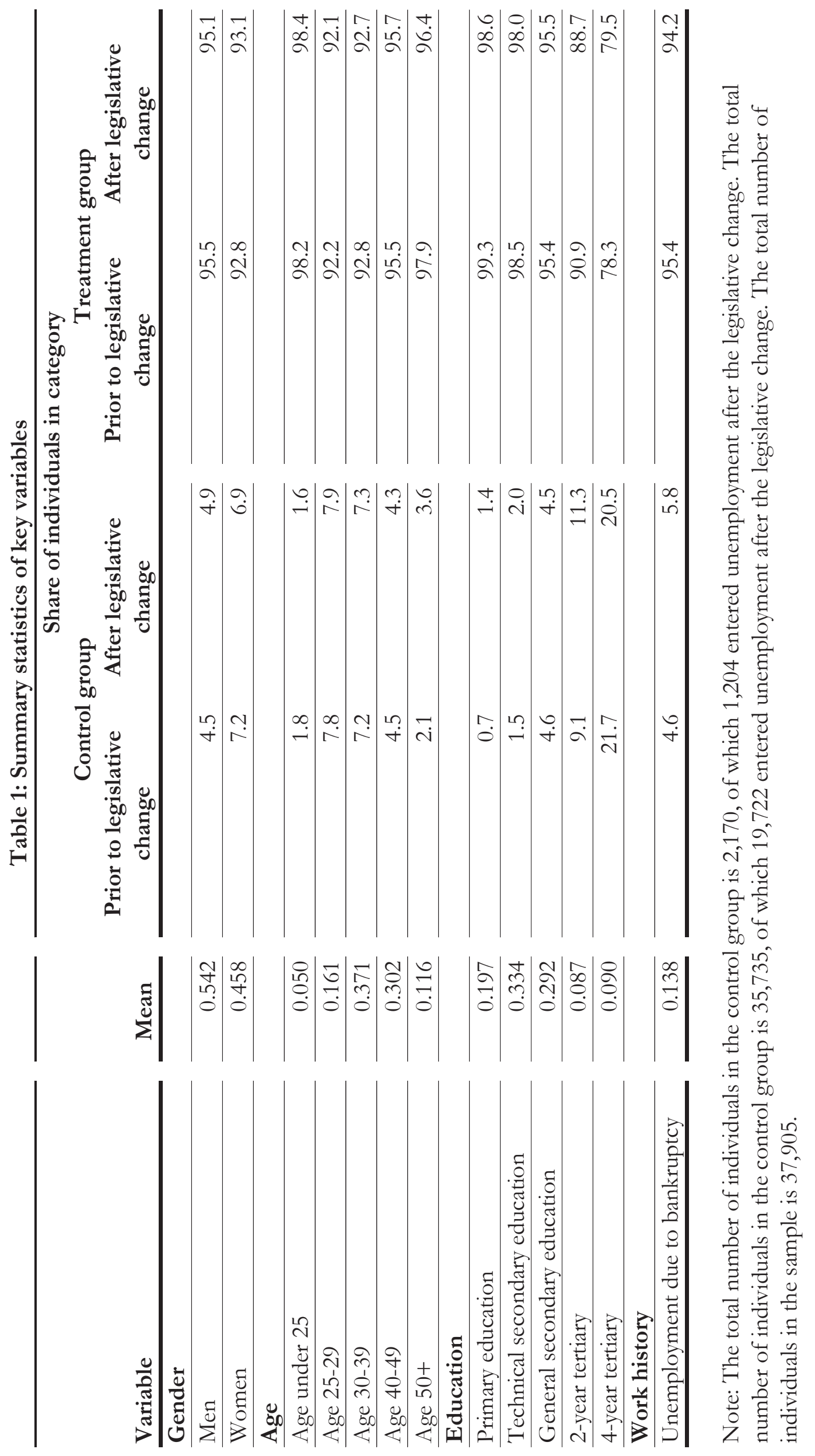


Table 2: Estimates from Cox proportional hazards model

\begin{tabular}{|c|c|c|c|c|c|}
\hline & $\begin{array}{c}\text { Baseline } \\
\text { (1) }\end{array}$ & $\begin{array}{c}\text { Larger } \\
\text { treatment } \\
\text { group } \\
\text { (2) }\end{array}$ & $\begin{array}{c}\text { Smaller } \\
\text { treatment } \\
\text { group } \\
(3)\end{array}$ & $\begin{array}{c}\text { Continuing firms } \\
\text { only } \\
\text { (4) }\end{array}$ & $\begin{array}{c}\text { Exiting firms } \\
\text { only } \\
\text { (5) }\end{array}$ \\
\hline \multicolumn{6}{|c|}{ Policy and time-varying variables (baseline: control group under old law) } \\
\hline \multirow[t]{2}{*}{$\gamma$ (interaction coefficient for $\alpha$ and $\beta$ ) } & $0.874 * *$ & $0.895^{* *}$ & $0.884 * *$ & $0.825^{* * *}$ & 1.092 \\
\hline & $(0.0466)$ & $(0.0470)$ & $(0.0539)$ & $(0.0475)$ & $(0.164)$ \\
\hline \multirow[t]{2}{*}{$\beta$ (included in the treatment group) } & $0.908^{* *}$ & $0.914 * *$ & $0.888^{* * *}$ & $0.906^{* *}$ & 0.911 \\
\hline & $(0.0366)$ & $(0.0374)$ & $(0.0401)$ & $(0.0387)$ & $(0.115)$ \\
\hline \multirow[t]{2}{*}{$\alpha$ (started receiving UB in 2011) } & 0.930 & $0.907^{* *}$ & 0.926 & 0.959 & 0.825 \\
\hline & $(0.0446)$ & $(0.0427)$ & $(0.0520)$ & $(0.0494)$ & $(0.115)$ \\
\hline \multicolumn{6}{|c|}{ UB design -- Potential benefit duration (baseline: potential benefit duration of 3 months) } \\
\hline \multirow[t]{2}{*}{6 months } & $0.808^{* * *}$ & $0.803^{* * *}$ & $0.807 * * *$ & $0.792^{* * *}$ & 1.051 \\
\hline & $(0.0232)$ & $(0.0227)$ & $(0.0239)$ & $(0.0241)$ & $(0.111)$ \\
\hline \multirow[t]{2}{*}{9 months } & $0.775^{* * *}$ & $0.770 * * *$ & $0.782^{* * *}$ & $0.742^{* * *}$ & 1.122 \\
\hline & $(0.0299)$ & $(0.0294)$ & $(0.0314)$ & $(0.0321)$ & $(0.130)$ \\
\hline \multirow[t]{2}{*}{1 year } & $0.633^{* * *}$ & $0.635^{* * *}$ & $0.627^{* * * *}$ & $0.598^{* * *}$ & 0.964 \\
\hline & $(0.0335)$ & $(0.0332)$ & $(0.0344)$ & $(0.0380)$ & $(0.126)$ \\
\hline \multirow[t]{2}{*}{18 or 19 months } & $0.527 * * *$ & $0.526^{* * *}$ & $0.527^{* * *}$ & $0.412^{* * *}$ & 1.163 \\
\hline & $(0.0432)$ & $(0.0428)$ & $(0.0446)$ & $(0.0420)$ & $(0.200)$ \\
\hline \multirow[t]{2}{*}{24 or 25 months } & $0.341^{* * *}$ & $0.333^{* * *}$ & $0.323^{* * *}$ & $0.277^{* * * *}$ & 0.745 \\
\hline & $(0.0495)$ & $(0.0477)$ & $(0.0496)$ & $(0.0509)$ & $(0.188)$ \\
\hline \multicolumn{6}{|c|}{ Work history (baseline: unemployed for reasons other than employer exit) } \\
\hline \multirow[t]{2}{*}{ Unemployed due to employer exit } & $1.564 * * *$ & $1.570^{* * *}$ & $1.548^{* * *}$ & & \\
\hline & $(0.0487)$ & $(0.0482)$ & $(0.0501)$ & & \\
\hline \multicolumn{6}{|l|}{ Gender (baseline: women) } \\
\hline \multirow[t]{2}{*}{ Men } & 0.965 & $0.951 * *$ & $0.948^{* *}$ & $0.950 * *$ & 1.104 \\
\hline & $(0.0222)$ & $(0.0215)$ & $(0.0225)$ & $(0.0236)$ & $(0.0719)$ \\
\hline \multicolumn{6}{|l|}{ Age (baseline: under 25 years old) } \\
\hline \multirow[t]{2}{*}{$25-29$} & 1.044 & 1.042 & 1.048 & 1.058 & 0.760 \\
\hline & $(0.0496)$ & $(0.0485)$ & $(0.0501)$ & $(0.0522)$ & $(0.143)$ \\
\hline \multirow[t]{2}{*}{$30-39$} & 0.981 & 0.963 & 0.984 & 0.978 & 0.796 \\
\hline & $(0.0462)$ & $(0.0447)$ & $(0.0468)$ & $(0.0481)$ & $(0.147)$ \\
\hline \multirow[t]{2}{*}{$40-49$} & 0.975 & 0.953 & 0.968 & 1.009 & $0.663^{* *}$ \\
\hline & $(0.0500)$ & $(0.0482)$ & $(0.0502)$ & $(0.0543)$ & $(0.126)$ \\
\hline \multirow[t]{2}{*}{$50+$} & $0.805^{* * *}$ & $0.800^{* * *}$ & $0.804^{* * *}$ & 0.907 & $0.421 * * *$ \\
\hline & $(0.0637)$ & $(0.0628)$ & $(0.0649)$ & $(0.0781)$ & $(0.0955)$ \\
\hline \multicolumn{6}{|c|}{ Education (baseline: primary school or less) } \\
\hline \multirow[t]{2}{*}{ Secondary school (technical) } & $1.216^{* * *}$ & $1.218^{* * *}$ & $1.220^{* * *}$ & $1.241 * * *$ & $1.168^{* *}$ \\
\hline & $(0.0404)$ & $(0.0400)$ & $(0.0408)$ & $(0.0468)$ & $(0.0809)$ \\
\hline \multirow[t]{2}{*}{ Secondary school (general) } & $0.863 * * *$ & $0.852^{* * *}$ & $0.853^{* * * *}$ & $0.845^{* * *}$ & 1.021 \\
\hline & $(0.0306)$ & $(0.0298)$ & $(0.0307)$ & $(0.0332)$ & $(0.0839)$ \\
\hline 2-year tertiary & $0.879 * * *$ & $0.872^{* * *}$ & $0.846^{* * *}$ & $0.885^{* *}$ & 0.923 \\
\hline & $(0.0403)$ & $(0.0392)$ & $(0.0409)$ & $(0.0440)$ & $(0.117)$ \\
\hline 4-year tertiary (or greater) & $1.077^{*}$ & $1.076^{*}$ & 1.064 & 1.072 & 1.118 \\
\hline & $(0.0469)$ & $(0.0458)$ & $(0.0483)$ & $(0.0500)$ & $(0.173)$ \\
\hline Observations & 156,450 & 162,271 & 147,202 & 134,869 & 21,581 \\
\hline Number of subjects & 37905 & 39305 & 35709 & 32472 & 5433 \\
\hline Number of Failures & 8942 & 9272 & 8383 & 7384 & 1558 \\
\hline Time at risk (years) & 7398 & 7675 & 6959 & 6366 & 1032 \\
\hline Log likelihood & -91025 & -94704 & -84819 & -73925 & -12907 \\
\hline
\end{tabular}

Notes: (1) contains individuals whose previous wage ranged from 730 to 1,313 EUR or 1,433 to 3000 EUR, (2) contains individuals whose previous wage ranged from 730 to 3000 EUR, (3) contains individuals whose previous wage ranged from 730 to 1,313 EUR or 1,433 to 2015 EUR. All specifications include controls for month of entry into unemployment. Sample is comprised of individuals who were eligible for unemployment benefits at the onset of unemployment. Failure is defined as exiting to employment; other exits from unemployment registry database are construed as censoring. See data section for details. Standard errors clustered by individual in parenthesis $(* * * \mathrm{p}<0.01, * * \mathrm{p}<0.05, * \mathrm{p}<0.1)$. 
Exit to

employment Exit to inactivity

(1)

(2)

Policy and time-varying variables (baseline: control group under old law)

\begin{tabular}{|c|c|c|}
\hline$\gamma$ (interaction coefficient for $\alpha$ and $\beta$ ) & $0.828^{* * *}$ & 0.676 \\
\hline & $(0.0477)$ & $(0.173)$ \\
\hline \multirow[t]{2}{*}{$\beta$ (included in the treatment group) } & $0.905^{* *}$ & $1.743^{* * *}$ \\
\hline & $(0.0386)$ & $(0.329)$ \\
\hline \multirow[t]{2}{*}{$\alpha($ started receiving UB in 2011) } & 0.956 & 1.008 \\
\hline & $(0.0492)$ & $(0.242)$ \\
\hline
\end{tabular}

UB design -- Potential benefit duration (baseline: potential benefit duration of 3 months)

\begin{tabular}{|c|c|c|}
\hline \multirow[t]{2}{*}{6 months } & $0.794 * * *$ & $0.552 * * *$ \\
\hline & $(0.0241)$ & $(0.0624)$ \\
\hline \multirow[t]{2}{*}{9 months } & $0.744 * * *$ & $0.546^{* * *}$ \\
\hline & $(0.0322)$ & $(0.0922)$ \\
\hline \multirow[t]{2}{*}{1 year } & $0.600 * * *$ & $0.337 * * *$ \\
\hline & $(0.0381)$ & $(0.0969)$ \\
\hline \multirow[t]{2}{*}{18 or 19 months } & $0.415^{* * *}$ & $0.368^{* *}$ \\
\hline & $(0.0422)$ & $(0.145)$ \\
\hline \multirow[t]{2}{*}{24 or 25 months } & $0.281 * * *$ & $4.69 \mathrm{e}-10^{* * *}$ \\
\hline & $(0.0517)$ & $(1.36 \mathrm{e}-10)$ \\
\hline \multicolumn{3}{|l|}{ Gender (baseline: women) } \\
\hline \multirow[t]{2}{*}{ Men } & $0.947 * *$ & 1.044 \\
\hline & $(0.0236)$ & $(0.0934)$ \\
\hline \multicolumn{3}{|c|}{ Age (baseline: under 25 years old) } \\
\hline \multirow[t]{2}{*}{$25-29$} & 1.064 & $0.669 * * *$ \\
\hline & $(0.0525)$ & $(0.0930)$ \\
\hline \multirow[t]{2}{*}{$30-39$} & 0.986 & $0.543^{* * *}$ \\
\hline & $(0.0485)$ & $(0.0746)$ \\
\hline \multirow[t]{2}{*}{$40-49$} & 1.018 & $0.506^{* * *}$ \\
\hline & $(0.0548)$ & $(0.0807)$ \\
\hline \multirow[t]{2}{*}{$50+$} & 0.911 & $0.589 *$ \\
\hline & $(0.0784)$ & $(0.179)$ \\
\hline \multicolumn{3}{|c|}{ Education (baseline: primary school or less) } \\
\hline \multirow[t]{2}{*}{ Secondary school (technical) } & $1.240^{* * *}$ & 0.919 \\
\hline & $(0.0468)$ & $(0.121)$ \\
\hline \multirow[t]{2}{*}{ Secondary school (general) } & $0.846^{* * *}$ & 0.848 \\
\hline & $(0.0332)$ & $(0.112)$ \\
\hline \multirow[t]{2}{*}{ 2-year tertiary } & $0.886 * *$ & 0.800 \\
\hline & $(0.0441)$ & $(0.144)$ \\
\hline \multirow[t]{2}{*}{ 4-year tertiary (or greater) } & 1.069 & 0.982 \\
\hline & $(0.0498)$ & $(0.169)$ \\
\hline Observations & 134,869 & 134,869 \\
\hline Number of subjects & 32472 & 32472 \\
\hline Number of Failures & 7384 & 569 \\
\hline Log likelihood & -74019 & -5662 \\
\hline
\end{tabular}

Notes: All specifications include controls for month of entry into unemployment. Sample is comprised of individuals who were eligible for unemployment benefits at the onset of unemployment. . See data section for details. Standard errors clustered by individual in parenthesis $\left(* * * \mathrm{p}<0.01,{ }^{* *} \mathrm{p}<0.05, * \mathrm{p}<0.1\right)$. 
www.celsi.sk

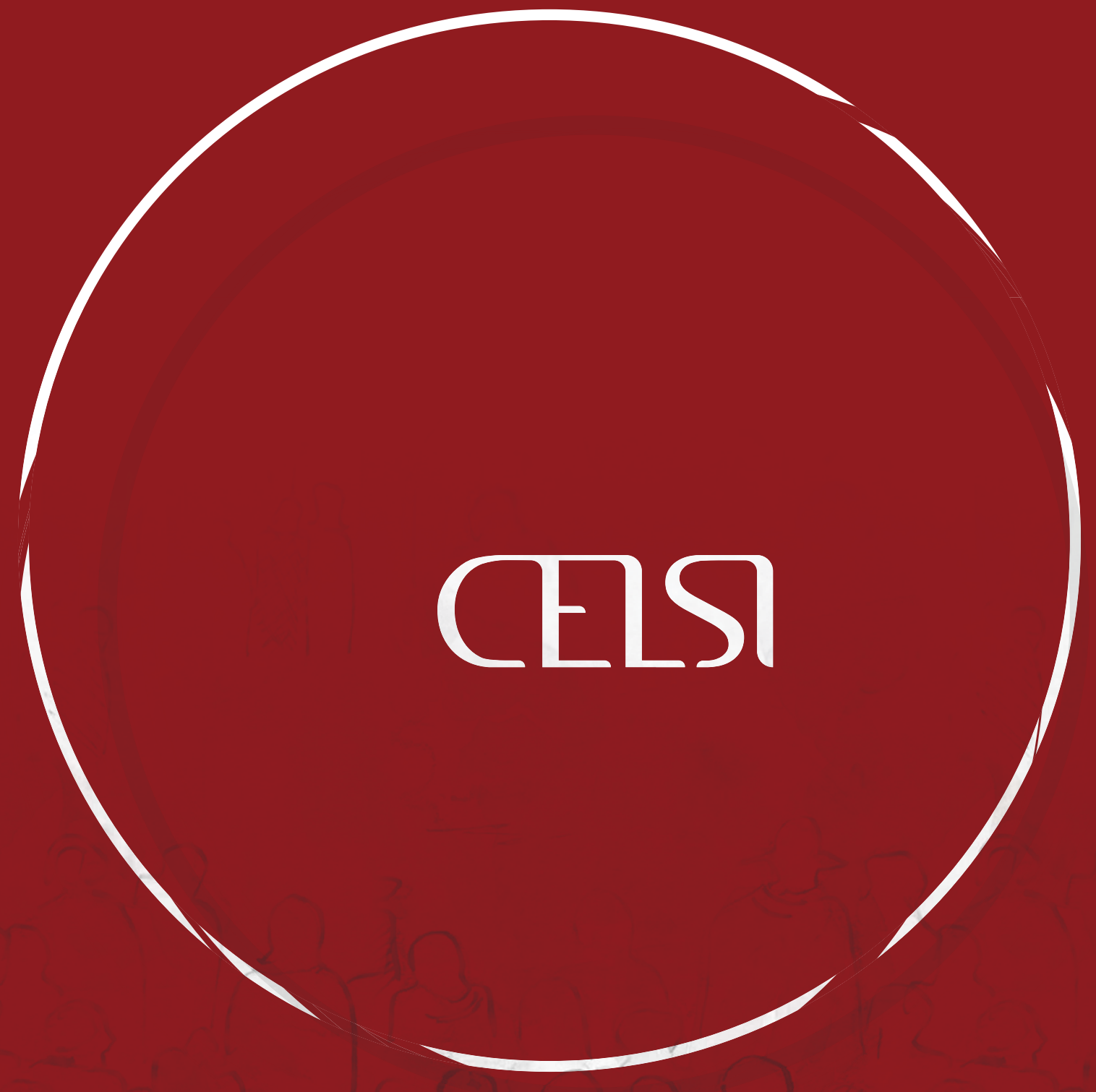

